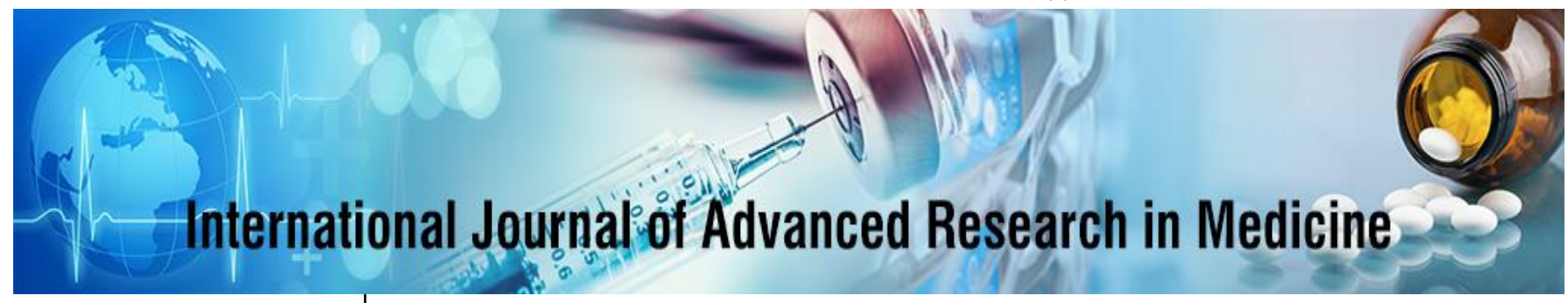

E-ISSN: 2706-9575

P-ISSN: 2706-9567

IJARM 2020; 2(2): 170-172

Received: 13-05-2020

Accepted: 19-06-2020

Dr. Anubhav Gupta

Assistant Professor,

Department of General

Medicine, JNUIMSRC, Jaipur,

Rajasthan, India

Dr. Kanika Vij

Tutor, Department of

Microbiology (Research

Methodology and Statistics),

Jaipur, Rajasthan, India
Corresponding Author:

Dr. Kanika Vij

Tutor, Department of

Microbiology (Research

Methodology and Statistics),

Jaipur, Rajasthan, India

\title{
A study of diet planning in diabetes using carbohydrate count
}

\section{Dr. Anubhav Gupta and Dr. Kanika Vij}

DOI: https://doi.org/10.22271/27069567.2020.v2.i2c.64

\begin{abstract}
Compared to fats and proteins, carbohydrates have the greatest impact on blood sugar except for dietary fibre, which is not digestible. According to the recent data of WHO there will be 333 million people with DM in the year 2030. To reduce the risk of diabetes micro vascular complications the effect of intensive insulin treatment of patients aiming to reduce A1C levels has shown effective results. Too much insulin or inadequate food intake lead to hypoglycaemia and potentially loss of consciousness and seizures. Considering these facts American Diabetes Association [ADA] emphasizes the importance of good glycaemic control to prevent chronic diabetic complications and suggest that changes in diet compositions of patients with DM are a relevant strategy to achieve an appropriate metabolic control. Carbohydrate Counting offers variability of food choices with potential for improving glycaemic control. This study puts in an effort to evaluate the influence of nutrition intervention on metabolic parameters in patients with type $2 \mathrm{DM}$ taking insulin according to carbohydrate counting method
\end{abstract}

Keywords: Diabetes, carbohydrate count, diet

\section{Introduction}

Our diet constitutes the food and drink that we consume. This consumption is based upon people's dietary choices affected by variety of factors like ethical and religious beliefs, clinical need or desire to control weight. There are variety of diets available in the market depending upon personal choices and clinical need of the body like crash diet, carbohydrate diet, low fat diet, detox diet, all depending on the person's need. Carbohydrates other than fats and protein form the important part of people diet with or without diabetes. It raises blood sugar and is processed by the insulin. Amount of consumption of carbohydrates affects the blood sugar level of people. The IOM (Institute of Medicine) has given the RDA for carbohydrate of $130 \mathrm{~g} / \mathrm{d}$ for adults and children aged $\geq 1 \mathrm{y}$, which is based upon person sugar and starch content. This value is based on the amount of sugars and starches required to provide the brain with an adequate supply of glucose. The acceptable macronutrient distribution range (AMDR) for carbohydrates of $45-65 \%$ of total calories, set by IOM. There is increasing prevalence of Type 2 diabetes mellitus. This is spreading as epidemic in the world. Not only adults, now the paediatric age group is also being affected. This is an emerging health problem in paediatric age group. There is no cure of the disease. The management of the disease is completely based upon lifestyle changes along with pharmacological treatment. The diabetes mellitus is often termed as a serious and costly disease. It has lot of microvascular complications which can controlled by having a check on A1C. The ADA (American Diabetes Association), changes in diet composition of diabetic people is right plan of action for appropriate metabolic control. As good glycaemic control can prevent and control Chronic diabetic complications.

Compared to fats and proteins, carbohydrates have the greatest impact on blood sugar except for dietary fiber, which is not digestible ${ }^{[1,2]}$. According to the recent data of WHO there will be 333 million people with DM in the year $2030^{[3]}$. To reduce the risk of diabetes micro vascular complications the effect of intensive insulin treatment of patients aiming to reduce A1C levels has shown effective results ${ }^{[4]}$. Too much insulin or inadequate food intake lead to hypoglycemia and potentially loss of consciousness and seizures. Considering these facts American Diabetes Association [ADA] emphasizes the importance of good glycemic control to prevent chronic diabetic complications and suggest that changes in diet compositions of 
patients with DM are a relevant strategy to achieve an appropriate metabolic control ${ }^{[5]}$. Carbohydrate Counting offers variability of food choices with potential for improving glycemic control ${ }^{[6,7,8]}$.

Balanced Carbohydrates are the key to success in preventing the complications arising due to Diabetes. Post prandial glucose levels as well as insulin responses to starches and sucrose are similar if the amount of carbohydrate is constant. Daily variability in energy and protein or fat are not significantly related to A1c. Sugars in any form are allowed to be the part of healthy eating pattern for all with diabetes. Sweet intake will replace the other form of carbohydrates in the meal pattern. Carbohydrates diet come from nutritious sources, such as fruits and vegetables, low fat or fat free dairy foods and grains. Sucrose does not increase glycemia to much extent. So, it can be substituted for food sources or can be taken up in diabetes with glucoselowering medication.

\section{Aims and Objectives}

To evaluate the influence of nutrition intervention on metabolic parameters in patients with type 2 DM taking insulin according to carbohydrate counting method.

\section{Materials and Methods}

The present work is a study comprising 100 patients with Type 2 DM who attended outpatient department of general medicine of JNUIMSRC, Jaipur.

Patients included in the study followed their normal dietary prescription without receiving any previous guidance on the diet based on carbohydrate counting. Questionnaire was given to evaluate their nutritional habits and present diet plan.

Present insulin dose, oral hypoglycemic drugs and records of blood sugar details were collected from the subjects. Records of HDL Cholesterol and LDL Cholesterol and details on whether the subject is a hypertensive are also recorded.

To evaluate dietary intake, patients were made to fill out a 3 days record (consecutive days) where information about food intake, meal time and places where meals are taken are included. Precise food, insulin, blood sugar were recorded to find Insulin/Carbohydrate ratio (I/C). An example is 1/15 which refers to 1 unit of insulin per $15 \mathrm{~g}$ of carbs eaten. Basic carb counting or exchange plan is used in this study. Complimentary information includes addition of salt to meals, intake of refined sugar, oil, sauces, industrialized food and way meals are prepared.

Method is known as estimated record of food intake since food is estimated by using conversion tables (portions determined in household measures like spoons, cups, shallow or deep plates). Some examples of foods and servings sizes that have $15 \mathrm{~g}$ of carbohydrates are: half cup of canned fruit (without juice), 1 cup of melon or berries, 2 tablespoons of dried fruit, half cup of cooked oat meal, half cup of cooked beans, peas or corn, 1 slice bread, 1 cup milk, one third cup of cooked long grained rice etc.

After careful analysis of the record, balanced diet was prescribed with the help of dietitian. By keeping present insulin dose as a constant a diet was prescribed using food conversion tables and their blood sugar was monitored. Dividing the carbohydrate intake for breakfast, lunch and supper which on a total is nsot less than $130 \mathrm{~g}$ per day with counseling the patients on exercise and a review after one month was done.

\section{Exclusion criteria}

Pregnant women and patients with mobility impairment were excluded from this study.

\section{Results}

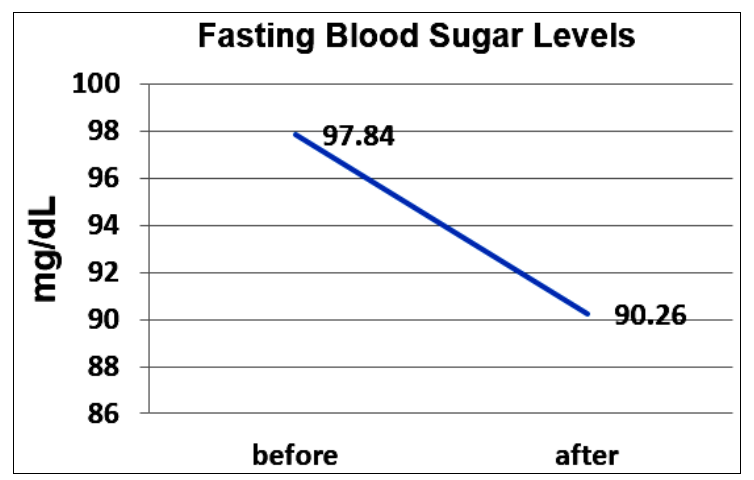

Fig 1: Mean Fasting Blood Sugar Levels pre and post intervention

Table 1: Paired Samples Correlations

\begin{tabular}{|l|c|c|c|c|}
\hline \multicolumn{2}{|l|}{} & $\mathbf{N}$ & Correlation & Sig. \\
\hline Pair 1 & FBS \& FBS 2 & 100 & .933 & .000 \\
\hline
\end{tabular}

The difference is statistically significant

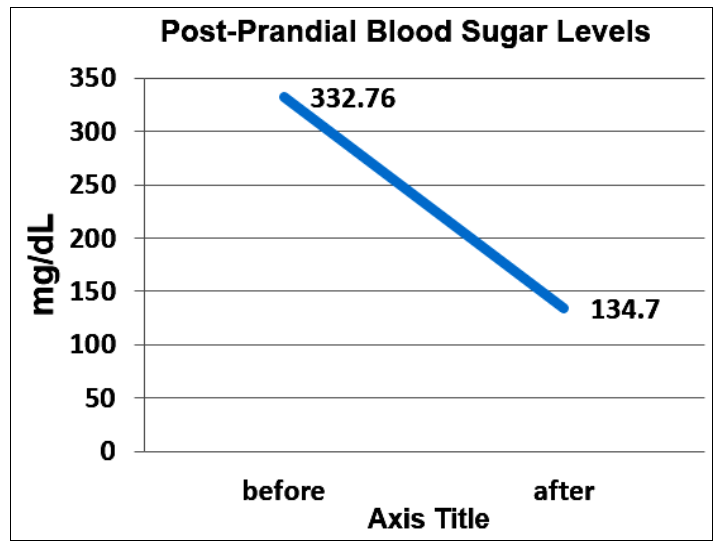

Fig 2: Mean Post-Prandial Blood Sugar Levels

Table 2: Paired Samples Correlations

\begin{tabular}{|l|c|c|c|c|}
\hline \multicolumn{5}{|c|}{ Paired Samples Correlations } \\
\hline \multicolumn{2}{|c|}{} & $\mathrm{N}$ & Correlation & Sig. \\
\hline Pair 1 & PPBS \& PPBS 2 & 100 & .647 & .000 \\
\hline
\end{tabular}

The difference is statistically significant

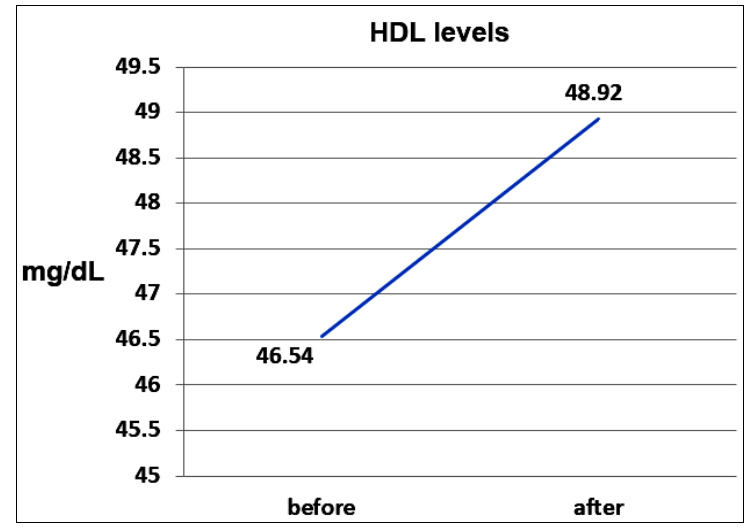

Fig 3: Mean HDL Levels 
Table 3: Paired Samples Correlations

\begin{tabular}{|l|c|c|c|c|}
\hline \multicolumn{2}{|l|}{} & $\mathbf{N}$ & Correlation & Sig. \\
\hline Pair 1 & HDL \& HDL 2 & 50 & .820 & .000 \\
\hline
\end{tabular}

The difference is statistically significant

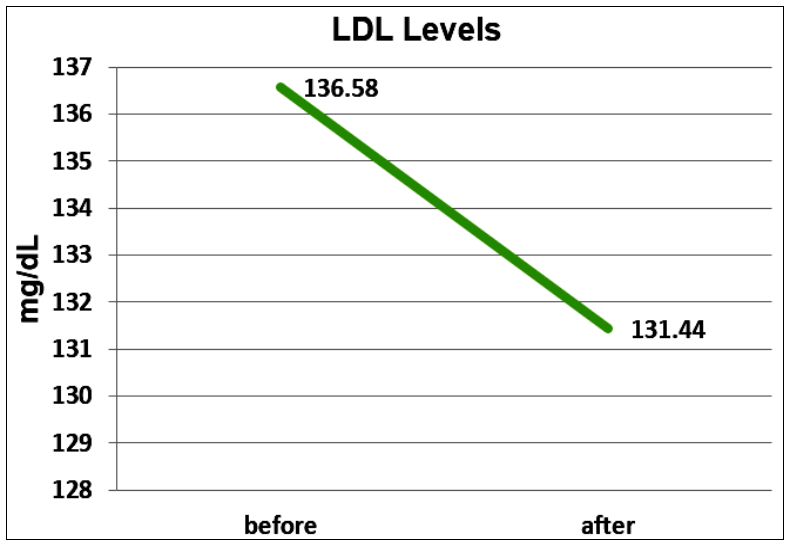

Fig 4: Mean LDL Levels

Table 4: Paired Samples Correlations

\begin{tabular}{|l|c|c|c|c|}
\hline \multicolumn{2}{|l|}{} & $\mathbf{N}$ & Correlation & Sig. \\
\hline Pair 1 & LDL \& LDL 2 & 50 & .813 & .000 \\
\hline
\end{tabular}

The difference is statistically significant

\section{Discussion}

Type 2 diabetes manifestation whether in young or old depend on lifestyle factors, out of which $55 \%$ is due to obesity. In order to prevent complications, modification of lifestyle and diet forms important factor for management of type 2 diabetes. The BMI maintenance and regular exercise causes significant reduction in increasing incidence of the disease. By following proper dietary and exercise measures, many people can even avoid medications. Diabetic diet plan focusing on carbohydrate counting is found useful in many studies. The carbohydrate count plan has shown to reduction of glycated hemoglobin, maintaining good control over blood glucose level. Diet plan is important for diabetic individual. Our major energy expenditure and 50\% to $60 \%$ of energy is through carbohydrates and rest from fat and proteins. The carbohydrate technique implementation is important. This nutritionist has the role of defining new treatment goals, to check the amount of carbohydrate intake and distribute it throughout the day. Carb counting is right way by which the course of disease can be put on check. Educating the society for diet in diabetics is an effective tool for management of the disease.

\section{Conclusion}

Proper diet management and exercise itself can control blood sugar level in some cases of type 2 diabetes.

\section{References}

1. Dias VM, Pandini JA, Nunes RR, Sperandei SL, Portella ES, Cobas RA, et al., Effect of the carbohydrate counting method on glycemic control in patients with type 1 diabetes. Diabetol Metab Syndr 2010;2:54.

2. Son JW, Jang EH, Kim MK, Kim IT, Roh YJ, Baek $\mathrm{KH}$, et al., Diabetic retinopathy is associated with subclinical atherosclerosis in newly diagnosed type 2 diabetes mellitus. Diabetes Res Clin Pract 2011;91(2):253-9.
3. Souto DL, Rosado EL, Use of carb counting in the dietary treatment of diabetes mellitus. Nutr Hosp 2010;25(1):18-25.

4. Martins MR, Ambrosio ACT, Nery M, de Cássia Aquino R, Queiroz MS. Assessment guidance of carbohydrate counting method in patients with type 2 diabetes mellitus. Prim Care Diabetes 2014;8(1):39-42.

5. Sluijs I, Beulens JWJ, Schouw YT van der, A DL van der, Buckland G, Kuijsten A, et al., Dietary Glycemic Index, Glycemic Load, and Digestible Carbohydrate Intake Are Not Associated with Risk of Type 2 Diabetes in Eight European Countries. J Nutr 2013;143(1):93-9.

6. Pereira MA, Nutrition and Type 2 Diabetes: Etiology and Prevention. CRC Press 2013, 238.

7. Colagiuri R, Diabetes: a pandemic, a development issue or both? Expert Rev Cardiovasc Ther 2010;8(3):305.

8. Nathan DM, Buse JB, Davidson MB, Ferrannini E, Holman RR, Sherwin R, et al., Medical management of hyperglycemia in type 2 diabetes: a consensus algorithm for the initiation and adjustment of therapy a consensus statement of the American Diabetes Association and the European Association for the Study of Diabetes. Diabetes Care 2009;32(1):193-203. 